\title{
JOSÉ MARÍA SBARBI, CERVANTISTA
}

\section{El CERVANTISMO DECIMONÓNICO GADITANO}

En el siglo XVIII se va a desarrollar de una manera muy peculiar un movimiento de revalorización de Cervantes y de su producción; aparecen de este modo dos corrientes interpretativas: el cervantismo y el quijotismo. Parece aceptado en la actualidad que, mientras el cervantismo se manifiesta como una actividad investigadora, con el propósito de dignificar la figura del escritor, el quijotismo se presenta como una forma de crítica que ofrece una doble vertiente; de un lado, supone una actitud crítica y beligerante hacia el barroquismo aún presente en las costumbres, y de otro puede ser un medio de expresar las nuevas tendencias estéticas.

No va a ser, sin embargo, el quijotismo la vertiente que se cultive durante el siglo XIX, sino que aparecerá una enorme labor de investigación sobre la vida de Cervantes, de la que surgirá toda una corriente - casi- ideológica: el cervantismo ${ }^{1}$.

Aunque pueda resultar exagerado hablar de ideología cuando nos referimos a la actividad de los cervantistas decimonónicos, no obstante, de la lectura pormenorizada de alguno de sus órganos de difusión - como la Crónica de los cervantistas - se puede extraer una manera peculiar y homogénea de entender la vida y la obra de Cervantes. A grandes rasgos se observa un desinterés casi absoluto por el teatro del autor, centrándose en las Novelas ejemplares, y

1 Cf. VALLEJO MÁRQUEZ, YolandA, «Aproximación al cervantismo decimonónico: El cervantismo gaditano", en Draco. Revista de Literatura Española, 5-6, 1993-1994, pp. 243-623. También de la misma autora, Adolfo de Castro (1823-1898). Su tiempo, su vida y su obra. Ayuntamiento de Cádiz, 1997. 
sobre todo en el Quijote; pero tras un breve análisis se detecta que el verdadero núcleo del movimiento cervantófilo es el propio Cervantes: su vida, sus opiniones, y una particular visión del mundo que los cervantistas configuran a partir de las obras del autor.

La Vida de Cervantes de Gregorio Mayans inicia, sin duda, una serie de trabajos importantes dedicados a «desentrañar» los aspectos menos conocidos de la biografía de Cervantes. No es una obra perfecta según los cánones de la historiografía moderna, pero de todos modos significa el punto de partida de una renovación total en los estudios cervantinos.

En 1797 aparece Vida de Cervantes de Manuel José Quintana, obra que a decir de Ramón León Máinez será la clave y marcará la pauta de los nuevos estudios cervantinos:

\footnotetext{
«La famosa biografía de Quintana fue precursora de un movimiento grandísimo de veneración a Cervantes. Fernández Guerra, Hartzenbusch, Valera, La Barrera, Rosell, Segovia, Dr. Thebussem, Asensio, Benjumea, Tubino y otros insignes de las letras patrias del XIX, publicaron estudios interesantísimos, que despertaron el deseo de emprender nuevos trabajos para dar mayor ampliación a todo cuanto con Cervantes se relacionara ${ }^{2}$.
}

A principios del XIX, Martín Fernández de Navarrete ampliará de forma considerable la biografía cervantina gracias a los documentos encontrados por Isidoro de Antillón en el Archivo de Indias hacia 1809. La indagación y la publicación de nuevas referencias ocupará gran parte de los trabajos cervantinos. Una carta, una obra anónima, un retrato... todo parece interesar de una forma desmedida a este grupo de estudiosos autodenominados «los misioneros de Cervantes" ${ }^{3}$.

Durante toda la centuria el interés por la biografia de Cervantes no decrece, antes bien, se intensifican los estudios sobre aspectos muy concretos, con el ánimo de dignificar su obra. Ramón León Máinez, por ejemplo, en 1877, con una obra titulada Vida de Cervantes, intentará realizar un compendio de los datos aportados por Mayans, Pellicer, de los Ríos, Fernández Navarrete y Quintana. Máinez y con él gran parte de los cervantistas, propugnan «descubrir cuanto con él se relaciona no sólo como literato, sino como hombre; no sólo en su vida pública, sino, con preferencia, en su vida particular e íntima» ${ }^{4}$.

\footnotetext{
2 MÁinez, RAmón León, Cervantes y su época. Jerez, Litografía Jerezana, 1901, p. 61 .

3 Vid. Portela, JuAn DE V., «Los misioneros de Cervantes», en Crónica de los cervantistas, tomo III, núm. II, 15 de julio de 1878.

4 máinez, Ramón león, Cervantes y su época, p. 59.
} 
La nómina de los cervantistas decimonónicos - sin incluir aquellos que alguna vez firmaron de forma esporádica artículos relacionados con el tema- sería muy extensa. Baste con recordar nombres como Hartzenbusch, Cayetano Alberto de La Barrera, José María Asensio, Mariano Pardo de Figueroa (el Doctor Thebussem), Adolfo de Castro, el autor de El Buscapié, que trajo de cabeza al mundillo de la literatura y que muchos consideraron como del propio Cervantes, Ramón León Máinez, que se hacía llamar «El bachiller cervántico», o nuestro José María Sbarbi, para tener una idea aproximada de las dimensiones de esta corriente.

Esta especie de fascinación desmesurada por la figura de Cervantes se concreta de forma inmediata en la conmemoración de las fechas más destacadas de la biografía cervantina. Hay que tener en cuenta que, por esta época, se desconocía con exactitud la fecha de nacimiento del autor - se dudaba entre el 28 y el 29 de septiembre- y por ello se celebraba con toda solemnidad la fecha de su muerte, el 23 de abril. Fecha que, por otra parte, ha llegado hasta la actualidad conservando parte de su significado festivo-literario. Siguiendo el testimonio del cervantista Máinez, la primera vez que se conmemoró en España la muerte de Cervantes fue en $1835^{5}$, en casa del Dr. Hernández en Zaragoza. La celebración fue íntima y apenas trascendió los círculos literarios de la ciudad. En 1841, una sociedad particular malagueña celebró con un carácter un poco más «oficial», el 225 aniversario del fallecimiento del autor.

Sin embargo, hasta los años sesenta, este tipo de efemérides cervantinas apenas significaban unas líneas en la prensa, o alguna que otra reunión de carácter más o menos privado. Es en 1867 cuando Máinez publica en La Palma de Cádiz un artículo donde se prestigiaba este tipo de solemnidades fúnebres. Curiosamente, el grupo surgido en Cádiz, liderado por el citado Ramón León Máinez, comienza a destacar por el elevado número de actos que se organizan cada 23 de abril:

"¡Podemos enorgullecernos los habitantes de Cádiz en haber celebrado con más entusiasmo que pueblo alguno de España el aniversario de la muerte de Cervantes!» ${ }^{6}$.

El caso gaditano rompe en cierta manera los esquemas prefijados por otros foros cervantistas que limitaban su actividad a la celebración anual. En 1867 Máinez creía que era de urgente nece-

5 Véase Máinez, RAMÓN LEÓN, «El Tercer Centenario del Quijote», en Crónica de los cervantistas, 2. ${ }^{\mathrm{a}}$ época, núm. 4-5, enero de 1905.

6 Máinez, RAmón LEÓn, editorial del suplemento del 25 de abril de 1872 de la Crónica de los cervantistas. 
sidad la creación de una academia cervántica y una publicación dedicada por entero a la vida y a la obra del escritor ${ }^{7}$. Ambos proyectos serían llevados a cabo en la ciudad, aunque con fortunas muy diferentes. El 7 de octubre de 1871 aparece por vez primera la Crónica de los Cervantistas, publicación literaria. Dedicada exclusivamente al Príncipe de los Ingenios. Esta revista no tiene una emisión regular, ni su director -Máinez- la pretende. Se trata de aglutinar el quehacer literario de los cervantistas en una obra conjunta editada en tres volúmenes ${ }^{8}$, que da cuenta del «movimiento, investigación, opiniones, folletos y libros que se perciben o aparecen en el campo cervantino» ${ }^{9}$.

El proyecto de Máinez estuvo en todo momento respaldado por algunas de las plumas más destacadas del momento. Así, pues, en el primer número de la revista colaboran José María Asensio, Aureliano Fernández Guerra, Adolfo de Castro, Mariano Pardo de Figueroa, Juan Eugenio Hartzenbusch, Narciso Campillo, Pascual Gayangos o Cayetano Alberto de la Barrera. Todos, independientemente de sus opiniones o de sus ideologías, parecen estar de acuerdo en que:

«El periódico actual viene, pues, a llenar ese vacío que se notaba en la república de las Letras. La Crónica de los Cervantistas procurará ser el fiel eco de todos los admiradores de Cervantes, sin distinción alguna de opinión, de patria o de nombre: no será órgano literario de determinados autores, sino que escuchará a todos» ${ }^{10}$.

Entre los objetivos de la publicación está el aceptar y publicar todos los trabajos de índole cervantina que se reciban; lo que, sin embargo, no resta brillantez a la revista, sino que le imprime un carácter abierto y bastante tolerante. Algo, esto último, que pretenden demostrar los redactores dándole un cierto aire de polémica.

7 MÁINez, RAMÓn LEÓN, "Aniversario de Miguel de Cervantes», en La Palma de Cádiz, 16 de abril de 1867

8 La rápida acogida de esta publicación hace que ya en 1904 sea muy difícil adquirir alguno de los tres volúmenes: "Los tres tomos que forman la colección contienen exquisita, variada, abundante y rica labor de superiores méritos, que solicita la atención y merece el aplauso de todos los hombres doctos. ¡Lástima que apenas puedan encontrarse los números de esta revista literaria, única en su clase!» («Presentación», en Crónica de los cervantistas, 2. ${ }^{a}$ época, núm. 1, 31 de julio de 1904).

9 Máinez, RAmón León, "Objeto de esta publicación», en Crónica de los cervantistas, tomo I, núm. I, 7 de octubre de 1871 .

10 Ibidem. 


\section{JOSÉ MARIA SBARBI}

\subsection{Apunte biográfico}

José María Sbarbi y Osuna nació en Cádiz en 1834. Su ministerio sacerdotal no le impidió dedicarse con ahinco a las actividades propias del filólogo, del folclorista y del musicólogo. Su carrera eclesiástica transcurrió como organista de diversas catedrales: Badajoz (desde 1857), Sevilla (1863) y Toledo (1868), para recalar finalmente en el Monasterio de la Encarnación de Madrid, donde pasó el resto de su vida dedicado al órgano y a trabajos eruditos de gran ambición, hasta su muerte ocurrida en 1910.

Según Cejador, no ingresó en la Academia de la Lengua por la oposición que le hizo Juan Valera, molesto por Un plato de garrafales. Juicio crítico de Pepita Jiménez (1874), en el que le sacó a relucir las faltas del lenguaje en la citada novela. Sí perteneció, en cambio, a la Academia de San Fernando que lo tuvo como individuo de número.

Su obra está compuesta por numerosas y variadas publicaciones, entre las que podemos destacar los diez tomos de su Refranero general español (1874), la Monografía de refranes, adagios y proverbios castellanos (1891) y Florilegio o ramillete alfabético de refranes $y$ modismos (1873). Sbarbi cultivó muy especialmente la paremiología, o ciencia de los refranes.

Otras obras suyas son: El Averiguador Universal en cuatro tomos (1868-1871-1876-1879), Diccionario de andalucismos, dos tomos que contienen unas seis mil papeletas, Álbum teresiano, Doña Lucía (1886), un juguetillo - según el autor-que puede definirse como novela histórica o historia novelesca, La filosofía de la música y Prontuario de definiciones musicales (1861) ${ }^{11}$.

\subsection{Sbarbi, cervantista}

El autor gaditano trató el tema cervantino en las siguientes obras: Intraducibilidad del Quijote, pasatiempo literario (1876), Cervantes, perito en geografía, In illo tempore y otras frioleras, bosquejo cervantino o pasatiempo quijotesco por cuatro costados (1903) y Cervantes teólogo (1870), de la que nos ocupamos ahora, por la polémica que suscitó su aparición ${ }^{12}$. Una polémica de poco interés,

11 Cf. PAYÁn SOTOMAYOR, P. M., "José María Sbarbi y Osuna», en Escritores gaditanos raros y olvidados (en prensa).

${ }_{12}$ SBARBI y OSUNA, José M. ${ }^{\mathrm{a}}$, Cervantes teólogo (carta que dirige al Sr. D. Mariano Pardo de Figueroa). Toledo, 1870. 
que apenas trasciende los límites de la revista de Máinez, pero que pretende testimoniar el encendido talante de sus colaboradores.

En efecto, las páginas de la Crónica de los Cervantistas son testigos de la controversia entre Sbarbi y Máinez sobre el presunto carácter de teólogo de Cervantes. Todo comienza cuando Ramón León Máinez en octubre de 1871 afirma que «Cervantes no fue teólogo», a propósito de la tesis defendida por Sbarbi, pues considera que es

«una verdad algo dudosa hasta ahora, y que creemos lo continuará siendo a pesar de los esfuerzos de ingenio y sutileza que ponga en práctica para conseguir lo contrario el autor del folleto que nos ocupa» ${ }^{13}$.

Y seguirá diciendo:

«Los conocimientos teológicos de Cervantes no tienen nada de científicos. Los mismos ejemplos que aduce en su opúsculo el Sr. Sbarbi para demostrar que el Ingenio alcalaíno fue teólogo, lo patentizan así... Católico creyente, hombre de rectos principios, amante de su patria y adorador de la religión de sus padres, habla de ella Cervantes con respeto, la ensalza, la sublima, vierte en sus obras el caudal de sus nobles ideas, derrama a torrentes consoladoras esperanzas, vuelve bien por mal, perdona a sus enemigos, no corroe la envidia su pecho magnánimo, desprecia la altivez, desdeña la ruin calumnia, despide de su bien tajada péñola dardos de encendida caridad o meritoria mansedumbre o resignación encantadora y sublime. ¿Se necesita para esto ser teólogo?» ${ }^{14}$

«No, en modo alguno. CERVANTES NO FUE TEÓlOgo. Fue, sí, como hemos insinuado antes, ilustrado, ilustradísimo en todo lo concerniente a su religión, a sus preceptos, a sus principios constitutivos y esenciales, y por eso habló de ellos con tanta exactitud como elocuencia. Ni más ni menos» ${ }^{15}$.

«El Sr. Sbarbi ha incurrido, pues, en un grave, gravísimo error al dar a Cervantes por teólogo en absoluto y fundadamente a su entender, cuando sólo debiera haberlo presentado como tal, pues que así le plugo, de un modo hipotético y relativo" ${ }^{16}$.

Curiosa esta polémica, pues llega a anunciarse antes de producirse. En el número 2 de la Crónica se inserta un artículo del mismo Sbarbi titulado «Preliminares de una polémica», en el que queda

«más íntimamente convencido de lo que ya lo estaba, de que Cervantes sí fue teólogo, y, en en su consecuencia, dispuesto a hacerle ver a V. que, o

13 Máinez, RAmón LeÓN, "Cervantes no fue teólogo", en Crónica de los cervantistas, núm. 1, octubre de 1871, p. 20.

${ }_{14}$ Íd., pp. 21-23.

15 Íd., p. 23.

16 Íd., p. 23. 
se encontraba soñando cuando enristró la péñola para defender la proposición contraria a la por mí sentada, o, si despierto, que no había comprendido el verdadero sentido de mi Carta, o ambas cosas a la vez ${ }^{17}$.

Tras aludir a sus muchas ocupaciones, promete:

\begin{abstract}
«Si para principios del entrante me concede el Topoderoso vida y salud, y no es su voluntad suprema el oponerme obstáculo alguno que contradiga la mía en el particular, le prometo a V. demostrarle paladinamente, y mediante pruebas en su mayor parte de redargución, lo erróneo de su aserto... y algo más» 18
\end{abstract}

Máinez acusa recibo y concluye:

"Yo, sin encerrarme en un círculo tan exclusivista, me atrevo a sostener que es dificultoso el demostrar que Cervantes fue teólogo, no siéndolo tanto el patentizar lo contrario. Con todo, tal vez pueda V. derribar con la piqueta de su pluma el edificio de mis razonamientos. Pero hasta entonces, Sr. Sbarbi, lo escrito, escrito está. CERVANTES NO FUE TEÓLOGO» ${ }^{19}$.

Todo esto da pie para que Sbarbi, a través de tres largas entregas defienda sus ideas con "Cervantes sí fue teólogo». Resumiremos algunas de estas ideas para que pueda observarse la actitud del presbítero gaditano:

«Creo que para la mejor inteligencia, debo comenzar mi defensa repitiendo lo que ya dije en mi opúsculo tocante a la acepción en que, para el caso presente, usaba yo la palabra teólogo; a saber: la de inteligente o docto en la teología, según la autoridad de la Academia Española en su Diccionario.

Dirígeme el Sr. Máinez los cargos, entre otros, de haber dicho yo que Cervantes fue teólogo perfecto, perfectisimo, consumado. Yo he buscado tales calificativos en mi folleto, y por vida mía que, leídas y releídas sus páginas, no he hallado tal cosa: sólo sí me he permitido calificarlo de verdadero teólogo (pág. 6); de teologo nada adocenado (pág. 17); de poseer un estudio nada superficial de la teología (pág. 11); de haber echado el resto de su pericia teológica en la canción de Feliciana (pág. 22); y poco después, de que bien hubiera podido escribir un sermón sobre el mismo o cualquier otro argumento, por poseer el caudal suficiente de conocimientos dogmáticos, morales y escriturarios, adquiridos no por el simple contacto con la sociedad, sino en fuerza de estudios expresamente hechos, ora fuese en la cátedra, ora en la lectura profunda y bien digerida de los autores en el recinto silencioso del gabinete. De esto a lo que el Sr. Máinez ha sentado, va tanta diferencia, o yo me engaño mucho, como de la noche a la mañana» ${ }^{20}$.

17 Sbarbi, José M. ${ }^{a}$, "Preliminares de una polémica», en Crónica de los cervantistas, núm. 2, noviembre 1871 , p. 44.

$18 I$ Í., p. 44.

19 MÁineZ, RAMón LEÓN, acuse de recibo en Crónica de los cervantistas, núm. 2, noviembre 1871 , pp. 44-45.

20 SBARBI, José M. ${ }^{\mathrm{a}}$, «Polémica. Cervantes sí fue teólogo», en Crónica de los cervantistas, p. 143. 
Sbarbi se pregunta:

"¿qué método han seguido Morejón, Caballero, Fernández y Martín Gamero para pintar respectivamente al Manco de Lepanto como médico, geógrafo, marino y jurisperito, sino el de entresacar aquellos pasajes de las obras inmortales del gran escritor en que luciera su pericia e inteligencia en dichas facultades? Pues eso mismo he hecho yo» ${ }^{21}$.

En efecto, la argumentación de Sbarbi se fundamenta en fragmentos bien seleccionados de las obras cervantinas, sobre todo de las Novelas ejemplares y, especialmente, del Quijote. Pues bien, de la Novela de las novelas, según su misma expresión, elegimos como ilustración estos pasajes:

«Sancho el bueno, vente tras mí, que Dios, que es proveedor de todas las cosas, no nos ha de faltar, y más andando tan en su servicio como andamos, pues no falta a los mosquitos del aire, ni a los gusanillos de la tierra, ni a los renacuajos del agua, y es tan piadoso, que hace salir su sol sobre buenos y malos, y llueve sobre los injustos y justos. Más bueno era vuestra merced, dijo Sancho, para predicador que para caballero andante. De todo sabían y han de saber los caballeros andantes, Sancho, dijo D. Quijote, porque caballero andante hubo en los pasados siglos que así se paraba a hacer un sermón o plática en mitad de un campo real, como si fuera graduado por la universidad de París; de donde se infiere que nunca la lanza embotó la pluma, ni la pluma la lanza» (Quijote, Parte primera, cap. 18) ${ }^{22}$.

«No más, Sancho, dijo a este punto D. Quijote: tente en buenas, y no te dejes caer, que en verdad que lo que has dicho de la muerte por tus rústicos términos es lo que pudiera decir un buen predicador. Dígote, Sancho, que si como tienes buen natural tuvieras discreción, pudieras tomar un púlpito en la mano e irte por ese mundo predicando lindezas. Bien predica quien bien vive, respondió Sancho, y yo no sé otras tologías. $\mathrm{Ni}$ las has menester, dijo D. Quijote; pero yo no acabo de entender ni alcanzar, cómo siendo el principio de la sabiduría el temor de Dios, tú, que temes más a un lagarto que a Él, sabes tanto. Juzgue vuesa merced, señor, de sus caballerías, respondió Sancho, y no se meta en juzgar de los temores o valentías ajenas, que tan gentil temeroso soy yo de Dios como cada hijo de vecino: y déjeme vuesa merced despabilar esta espuma, que lo demás todas son palabras ociosas, de que nos han de pedir cuenta en la otra vida» (Íd., cap. 21) ${ }^{23}$.

"Oía todo esto Sancho, y dijo entre sí: este mi amo, cuando yo hablo cosas de meollo y de sustancia, suele decir que podría yo tomar un púlpito en las manos, y irme por ese mundo adelante predicando lindezas; y

${ }_{21}$ Id., p. 221. Se refiere Sbarbi a los siguientes trabajos: Bellezas de medicina práctica descubierta en el Ingenioso caballero don Quijote de la Mancha, de ANTONIO Hernández de Morejón; Pericia geográfica de Cervantes, de Fermín Caballero; Cervantes marino, de CESÁREO FERnÁNDEZ; y Cervantes jurisperito, de ANTONIO MARTín GAMERO.

${ }_{22}$ Íd., p. 219.

${ }_{23}$ Íd. 
yo digo dél, que cuando comienza a enhilar sentencias y a dar consejos, no sólo puede tomar un púlpito en las manos, sino dos en cada dedo, y andarse por esas plazas a qué quieres boca. Válate el diablo por caballero andante, que tantas cosas sabes: yo pensaba en mi ánima, que sólo podía saber aquello que tocaba a sus caballerías; pero no hay cosa donde no pique, y deje de meter su cucharada» (Íd. cap. 22) ${ }^{24}$.

«El diablo me lleve, dijo a esta sazón Sancho entre sí, si este mi amo no es teólogo, y si no lo es, que lo parece como un huevo a otro" (Íd., cap. 27). ...Así es que le vemos constantemente moralizador y catequista; pero no como quiera, sino trascendiendo a la legua a la esencia escolástica... En vista, pues, de todo lo ya manifestado, digo, y no puedo por menos de sostener que CERVANTES Sí FUE TEÓLOGO" ${ }^{25}$.

La polémica Sbarbi-Máinez queda, en principio, así zanjada. Para nosotros ha sido una buena excusa para acercanos a uno de los personajes que mejor encarnó el ambiente decimonónico gaditano en torno a Cervantes.

PEDRo PAYÁn Sotomayor

Universidad de Cádiz

${ }_{24}^{24} \quad$ Id.
${ }_{25}$ Íd, pp. $219-221$. 